\title{
Long-term Prospective Randomized Comparison Between Total Extraperitoneal Laparoscopic and Lichtenstein Hernioplasty in Treatment of Recurrent Inguinal Hernia
}

\author{
Ibrahim Othman, MD; Hamdy Abdel Hady, MD.
}

\author{
Department of General Surgery, Tanta University, Tanta, Egypt.
}

\begin{abstract}
This trial aimed to compare the feasibility of the total extraperitoneal (TEP) laparoscopic technique with the Lichtenstein hernioplasty in treating recurrent inguinal hernias.

Patients and methods: This prospective randomized multicenter study included 62 patients with unilateral recurrent inguinal hernia randomly categorized into 2 groups. Group A included 32 patients operated on by TEP laparoscopic hernioplasty. They were compared to 30 patients treated by conventional Lichtenstein hernioplasty (Group B). Mean length of follow up was 82.1 \pm 14.7 months in group A and 82.9 \pm 13.6 months in Group B.

Results: Mean operative time was $66.2 \pm 11.2$ minutes in group A versus $48.6 \pm 9.86$ minutes in group $B(p<.0001)$. First postoperative day pain score was $1.88 \pm 0.619$ versus $2.53 \pm 0.743$ (p0.012). Group A patients needed $2.12 \pm 0.719$ ampoules of $100 \mathrm{mg}$ Pethedine in the first postoperative day versus $3.07 \pm 1.62$ ampoules in group B patients for analgesia (p0.044). Hospitalization time was $1.31 \pm 0.602$ days and $1.47 \pm 0.990$ days (p0.60). Time to return to normal activity was $13.9 \pm 3.77$ days and $17.9 \pm 3.64$ days (p0.0056). We had to convert 3 patients (4.8\%) to the open repair due to lack of experience at the start of our research. In group B, Postoperative seroma occurred in 1 patient (1.6\%), surgical site infection in 1 patient (1.6\%) and 2 patients $(3.2 \%)$ suffered from chronic pain that started after operation. One patient markedly improved after 6 months while the other suffered from persistent low grade pain that failed to improve until the end of the study (p: 0.65). Hernia recurrence occurred in 1 patient (1.6\%) in either groups 15 and 37 months after operation (p0.96). Patient satisfaction score was $8.25 \pm 1.39$ versus $7.33 \pm 1.18$ ( $p 0.058$ )

Conclusion: Compared to open Lichtenstein hernioplasty, laparoscopic TEP approach for repair of recurrent inguinal hernia is technically feasible, safe and effective, with good clinical outcome. It is associated with longer operative time but reduced post-operative pain, analgesic requirement, and infection rate and earlier return to normal activities. The complication rate and recurrence rate were equal but patients were more satisfied.
\end{abstract}

Key words: Total extraperitoneal laparoscopic hernioplasty, Lichtenstein hernioplasty, recurrent inguinal hernia

\section{Introduction:}

Hernia was present in the human history from its very beginning. The oldest epoch from ancient Egypt to $15^{\text {th }}$ century BC. The Egyptian Papyrus of Ebers described hernia as swelling that comes out during coughing. Introduction of anesthesia and antiseptic procedures constituted the beginning of modern hernia repair under tension. Recurrence rate during four years was $100 \%$

and postoperative mortality gained even $7 \%$. The turning point in hernia surgery was discovery of synthetic polymers by Carothers in 1935. The first tensionless technique described by Lichtenstein was based on strengthening of the posterior wall of inguinal canal with prosthetic material. Lichtenstein published the data on 1,000 operations with Marlex mesh without any recurrence in 5 years after surgery. ${ }^{1}$ 
Mesh hernioplasty became widely used, and the previously used procedures were almost entirely displaced by the tension-free Lichtenstein hernioplasty. $^{2}$ Recent reports have presented with less impressive vast variety of recurrence rates of up to $20 \%$ for primary hernia and up to $30 \%$ for recurrent hernia repair. ${ }^{3-5}$ After the introduction of laparoscopic techniques, it was evident that the laparoscopic approach and the Lichtenstein procedure of treating primary inguinal hernias were equal in the means of recurrence.6,7 The laparoscopic approach has been associated with less postoperative pain, decreased post-operative consumption of analgesics, shorter hospital stays, less chronic pain, and increased patient satisfaction. ${ }^{8-17}$

Recurrent hernia had previously been considered to be more challenging to manage than primary hernia, since performing a dissection for a recurrent hernia is more difficult due to the hard scar tissue and the frequently altered anatomy. ${ }^{17}$ Some researchers have reported that the rerecurrence rate after the laparoscopic total Extraperitoneal (TEP) repair of a recurrent hernia is low. ${ }^{18-19}$ Few studies thus far have compared laparoscopic techniques and Lichtenstein procedure in treating recurrent inguinal hernias.

The aim of this prospective randomized trial was to compare the feasibility of the TEP laparoscopic technique with the Lichtenstein hernioplasty in treating recurrent inguinal hernias.

\section{Patients and methods:}

This multicenter prospective randomized study was performed in the General Surgery Department, Tanta University Hospitals, Egypt, Ahmad Maher Teaching Hospital, Cairo, Egypt, and Ghodran General Hospital, Kingdom of Saudi Arabia during the period from May 2003 to October 2012 on 62 patients with unilateral recurrent symptomatic inguinal hernia. Patients with a clinically evident bilateral hernia, patients preferring either operative technique, patients refusing to participate in the study were excluded from the study. Full explanation of procedures; possible complications and patient consent were assured before inclusion in the research. The study protocol was approved by the Ethics Committee of General Surgery Department, Tanta University Hospitals.

Patients were randomly categorized by surgery clinic secretary into 2 groups through sealed envelopes in a blinded randomized manner. Group A included 32 patients operated on by TEP laparoscopic hernioplasty. This group was compared to 30 patients treated by conventional Lichtenstein hernioplasty (Group B).

All patients underwent detailed medical history, clinical examination and abdominal ultrasound examination in addition to routine hematological and biochemical investigations for preparation for general anesthesia.

Patients were hospitalized on the day of surgery. All patients received a single dose of Augmentin 1.2 grams 30 minutes prior to surgery.

The TEP laparoscopic hernioplasty was performed under general anesthesia. Through a subumbilical incision the preperitoneal space was created using balloon dissection. Carbon dioxide was insufflated through a blunt tip trocar (pressure, $12-15 \mathrm{~mm} \mathrm{Hg}$ ). A second trocar was placed halfway the umbilicus and pubic bone. The space of Bogros was created with isolation of the spermatic cord. The third trocar was placed medial of the anterior superior iliac spine. A $12 \times 15 \mathrm{~cm}$ polypropylene mesh was placed over the myopectineal orifice of Fruchaud. Mesh fixation was not performed routinely, but it was sometimes fixed to Coopers ligament with tackers.

The Lichtenstein hernioplasty was performed according to the original description of the technique. ${ }^{2}$ Spinal anesthesia was used. The hernia sac was dissected and reduced to the preperitoneal space without opening or ligation. The hernia sac was not opened except when the contents of the hernia was fixed to the hernia site. To close the hernia site, a polypropylene mesh of $7.5 \times 15 \mathrm{~cm}$, was fashioned and placed with an overlap of the pubic bone. The mesh was fixed with a monofilament non absorbable 
suture. The surgeon had to report whether the ilioinguinal nerve and the iliohypogastric nerve were identified and spared. The external oblique fascia was closed with absorbable sutures.

The mesh used in both techniques was a polypropylene monofilament mesh (Prolene mesh, www.ecatalog.ethicon.com). In the TEP laparoscopic procedures, tackers (Tacker Fixation Device, www.autosuture.com) were sometimes used to attach the mesh.

Patients were allowed to drink 3 hours after recovery. Analgesia was given in the form of $100 \mathrm{mg}$ Pethedine on recovery and another $100 \mathrm{mg}$ Pethedine intramuscularly after 12 hours if the patient complains of pain. Postoperative pain was measured 6 hourly after surgery using pain visual analog scale. ${ }^{20}$ Patients were discharged from hospital in the first post-operative morning. Patients were followed in visits at three day interval for two weeks then every 3 months. Patients who did not come for follow up were contacted by telephone and interviewed about chronic pain and recurrence. Any patient reporting recurrence in the operated groin was scheduled for an outpatient clinic check. Patients were encouraged to visit the clinic at any time if they have any problem. The total follow-up time was calculated based on the last visit to the outpatient clinic or the contact via telephone.

Patient satisfaction score was designed by asking patients to express their satisfaction in a numerical score from 0 to 10 one month after surgery. The preoperative factors recorded included American Society of Anesthesiologists (ASA) ${ }^{21}$ risk group. Primary complications included infections and formation of hematomas or seromas. A superficial infection was defined as an infection not requiring surgical treatment. A deep infection was defined as an infection at or near the site of hernia surgery that required surgical intervention. Hematoma and/or seroma formation was considered a primary complication even if it resorbed spontaneously. Late complications included recurrence and chronic pain. The prevalence of late complications was evaluated during the visits at the outpatient clinic as well as during the telephone interview.

Statistical analysis:

Quantitative variables were expressed as mean $\pm \mathrm{SD}$. Qualitative variables were expressed as frequency and percent. Quantitative parametric variables were compared between the two groups using the unpaired student t-test, quantitative nonparametric variables were compared using Mann-Whitney test. Qualitative variables were compared using Chi-square test or Fisher exact test when the criteria for using Chi-square were not sufficient. The power used was 0.80 while the level of significance was $5 \%$.

\section{Results:}

Group A included 32 patients operated by TEP laparoscopic hernioplasty. This group was compared to 30 patients treated by conventional Lichtenstein hernioplasty (Group B). The mean length of follow up was $82.1 \pm 14.7$ months in group A patients and $82.9 \pm 13.6$ months in group B patients. The demographic characteristics and clinical data of patients studied are summarized in Table (1).

\section{Operation time:}

In group A, operative time ranged from $45-$ 95 minutes (mean operative time: $66.2 \pm 11.2$ minutes). In group B, operative time ranged from 35-60 minutes (mean operative time: $48.6 \pm 9.86$ minutes). The difference between the two groups was statistically significant (p: $<0.0001)$.

Postoperative pain:

Postoperative pain score measured first day after surgery was $1.88 \pm 0.619$ in group A patients versus $2.53 \pm 0.743$ in group B patients (p: 0.012). Group A patients needed a mean of $2.12 \pm 0.719$ ampoules of $100 \mathrm{mg}$ Pethedine for analgesia. Group B patients needed a mean of $3.07 \pm 1.62$ ampoules of $100 \mathrm{mg}$ Pethedine for analgesia (p: 0.044). 


\section{Hospitalization time}

Hospitalization time ranged from 1-4 days in both groups. Mean hospitalization time was $1.31 \pm 0.602$ days in group A. In group B, mean hospitalization time was $1.47 \pm 0.990$ days. The difference between the two groups was statistically insignificant (p:0.60).

Time to return to normal activity:

Time to return to normal activity ranged from 10-21 days in group A (mean time: $13.9 \pm 3.77$ days). In group $\mathrm{B}$, time to return to normal activity ranged from 10-24 days (mean time: 17.9 \pm 3.64 days). The difference between the two groups was statistically significant (p 0.0056).

\section{Complications:}

We had to convert 3 patients $(4.8 \%)$ to the open repair due to lack of experience at the start of our research. Postoperative seroma occurred in 1 patient $(1.6 \%)$ in group B. He was successfully treated conservatively. One patient $(1.6 \%)$ in group B developed surgical site infection. He was managed by proper antibiotic according to culture and sensitivity result. Two patients (3.2\%) suffered from chronic pain that started after operation. One patient markedly improved after medical treatment for 6 months. The other patient suffered from persistent low grade pain that failed to improve until the end of study. The difference between the complication rates in two groups was statistically insignificant (p: $0.65)$.

\section{Recurrence:}

Hernia recurrence occurred in 1 patient $(1.6 \%)$ in either group. In group A recurrence occurred 15 months after operation while in group B recurrence occurred 37 months after operation. It was the first rerecurrence in both cases. Group A patient was treated by Lichtenstein Hernioplasty while Group B patient was treated by TEP Laparoscopic Hernioplasty. No rerecurrence happened to them until the end of this study. The difference between the recurrence rates in two groups was statistically insignificant (p: 0.96). Postoperative complications are summarized in
Table (2).

Patient satisfaction score:

The mean patient satisfaction score for group A patients was $8.25 \pm 1.39$ versus 7.33 \pm 1.18 for Group B patients. The difference between the two groups was statistically significant (p: 0.058).

\section{Discussion:}

In our study, recurrent direct inguinal hernia was observed more often than indirect hernia. This goes with the findings of Choi. ${ }^{22} \mathrm{Lau}^{23}$ reported that occurrence of direct recurrent hernia reflects an inadequate reinforcement of the posterior wall by suture herniorrhaphy in the initial repair, and technical error or tension on the repair were possible contributing factors. Several studies have suggested that the potential causes for indirect recurrence includes missed hernia, incomplete dissection or low ligation of the sac, as well as incomplete restoration of the internal ring. ${ }^{24,25}$

The recurrence rate after primary inguinal hernia repair has been reported to be $8-25 \% .{ }^{26,27}$ The recurrence rate after laparoscopic TEP repair for recurrent inguinal hernia was not higher than that after primary hernia repair, and it even reached $0 \%$ in some studies. ${ }^{28-30}$ Lowham et al. ${ }^{31}$ reported that a major cause for recurrence after laparoscopic TEP repair was technical errors, including inadequate dissection of the space, an insufficient size of the prosthesis, and incorrect mesh positioning.

Dissection and making a space are more difficult in patients with recurrent inguinal hernia due to adhesion and the hard scar tissue, and the recurrence rate after hernioplasty could be higher for recurrent inguinal hernia than that for primary inguinal hernia. Schumpelick et al. ${ }^{32}$ suggested that the 5-year recurrence rate of modern inguinal hernia repairs has reached $1-3 \%$ for primary hernias and $3-5 \%$ for recurrent hernias. The treatment for recurrent inguinal hernia is substantially more complicated than the treatment for primary inguinal hernia. This is due to the need for a tension-free repair 
Table (1): The demographic characteristics and clinical data of patients.

\begin{tabular}{|l|l|l|l|}
\hline & \multicolumn{1}{|c|}{ Group A } & \multicolumn{1}{|c|}{ Group B } & \multicolumn{1}{|c|}{ P } \\
\hline Age & 58.212 .3 & 61.513 .8 & 0.49 \\
\hline $\begin{array}{l}\text { Gender } \\
\text { Males }\end{array}$ & $\begin{array}{l}31(50 \%) \\
1(1.6 \%)\end{array}$ & $\begin{array}{l}28(45.2 \%) \\
2(3.2 \%)\end{array}$ & 0.96 \\
\hline Memales & $30.7 \pm 4.56$ & $29.7 \pm 4.38$ & 0.56 \\
\hline Occupation & $18(29.0 \%)$ & $20(32.3 \%)$ & \\
Manual worker & $12(19.4 \%)$ & $10(16.1 \%)$ & \\
\hline Intellectual worker & $2(3.2 \%)$ & & \\
\hline Housewives & $124(38.7 \%)$ & $20(32.3 \%)$ & \\
\hline Current smoking & $12(19.4 \%)$ & $16(25.8 \%)$ & \\
\hline Comorbidities & $1.38 \pm 5.0$ & $1.53 \pm 0.516$ & 0.39 \\
\hline Mean ASA ranking & $6(9.7 \%)$ & $4(6.5 \%)$ & \\
\hline Recurrence symptoms & $3(4.8 \%)$ & $4(6.5 \%)$ & \\
Bulging & $23(37.1 \%)$ & $22(35.5 \%)$ & \\
\hline Pain & $2(3.2 \%)$ & $4(6.5 \%)$ & \\
\hline Both & $18(29.0 \%)$ & $21(33.9 \%)$ & \\
\hline Scrotal hernia & $14(22.6 \%)$ & $9(14.5 \%)$ & \\
\hline Primary hernia type & $1.56 \pm 0.727$ & $1.53 \pm 0.743$ & 0.91 \\
\hline Direct & $4.38 \pm 2.60$ & $4.47 \pm 2.97$ & 0.93 \\
\hline Indirect & $4(6.6 \%)$ & $6(9.7 \%)$ & \\
\hline Mean number of earlier hernia repairs & & & \\
\hline Mean time from last hernia repair, years & & & \\
\hline Previous abdominal surgery & & & \\
\hline
\end{tabular}

Table (2): Postoperative complications in both groups.

\begin{tabular}{|l|l|l|}
\hline Post operative complication & Number & Percentage \\
\hline Group A & & \\
Conversion to open procedure & 3 & $(4.8 \%)$ \\
Recurrence & 1 & $(1.6 \%)$ \\
\hline Group B & & \\
Seroma & 1 & $(1.6 \%)$ \\
Superfacial wound infection & 1 & $(1.6 \%)$ \\
Chronic pain & 2 & $(3.2 \%)$ \\
Recurrence & 1 & $(1.6 \%)$ \\
\hline
\end{tabular}

and closure of all potential hernia sites, the difficult dissection of scar tissue, and the altered anatomic situation.

The results of our study show that the TEP laparoscopic approach to recurrent inguinal hernia is superior to the Lichtenstein hernioplasty in several aspects affecting patient satisfaction. Preoperatively, there were no differences between the study groups. Therefore, the groups were comparable. The groups are also easily comparable to the general population because the study groups were consecutive patients referred from the outpatient clinic. 
Table (3): Comparison of postoperative data of both groups.

\begin{tabular}{|l|l|l|l|}
\hline & \multicolumn{1}{|c|}{ Group A } & \multicolumn{1}{c|}{ Group B } & \multicolumn{1}{c|}{ P } \\
\hline Operation time & $66.2 \pm 11.2$ minutes & $48.6 \pm 9.86$ minutes & $<0.0001$ \\
\hline Postoperative pain score & $1.88 \pm 0.619$ & $2.53 \pm 0.743$ & 0.012 \\
\hline Analgesics & $2.12 \pm 0.719$ Ampoules & $3.07 \pm 1.62$ Ampoules & 0.044 \\
\hline Hospitalization time & $1.31 \pm 0.602$ days & $1.47 \pm 0.990$ days & 0.60 \\
\hline Return to normal activity & $13.9 \pm 3.77$ days & $17.9 \pm 3.64$ days & 0.0056 \\
\hline Complications & 4 patients & 5 patients & 0.65 \\
\hline Recurrence & 1 patient & 1 patient & 0.96 \\
\hline Patient satisfaction score & $8.25 \pm 1.39$ & $7.33 \pm 1.18$ & 0.058 \\
\hline
\end{tabular}

There were 1 recurrence (1.6\%) after the TEP laparoscopic approach and 1 recurrence after Lichtenstein hernioplasty $(1.6 \%)$, the difference was statistically insignificant (p:0.96). In other studies concerning the treatment of recurrent hernias, the recurrence rate varies between $0.4 \%$ and $8.3 \%$ for laparoscopic techniques and between $1 \%$ and $15.6 \%$ for the Lichtenstein procedure. $10,12,15,33$ In this study, the recurrence rate was $3.2 \%$ for both procedures. These rates are thus comparable with earlier studies. The TEP laparoscopic approach recurrence occurred 15 months after operation while the Lichtenstein hernioplasty recurrence occurred 37 months after operation. According to Feliu and colleagues, ${ }^{12}$ possible recurrences after a laparoscopic hernia repair for recurrent inguinal hernia appear before 12 months. After an open recurrent hernia repair, most recurrences become evident at 30-60 months. With a follow-up of more than 80 months, we do not expect to see any more recurrences in either group.

Chronic pain in the inguinal region was reported during follow up in the group treated by Lichtenstein hernioplasty. Other studies of recurrent hernias ${ }^{12,16}$ reported a higher prevalence of chronic pain after open hernia repair compared with a laparoscopic approach. The reason for this is the difficulty to identify nerve structures when operating through scar tissue formed after the previous surgical intervention. The mesh frequently causes temporary discomfort during the first year after surgery independent of the surgical method used. This discomfort at the inguinal region then subsides when the mesh integrates permanently with the abdominal wall. Pain or neuralgia has been difficult to define and, therefore, the aspect of chronic pain or neuralgia has been omitted in many studies.

In our study, the patients who underwent the TEP laparoscopic repair experienced less postoperative pain and the duration of their sick leave was shorter. Concerning recurrent hernias, 4 out of 5 studies concluded that a laparoscopic approach was superior to an open technique by virtue of diminished postoperative pain and the patients accelerated return to normal activity. ${ }^{10,12,15,16,17}$ One study detected no difference between the 2 operative approaches with regard to the duration of sick leave and postoperative consumption of analgesics. ${ }^{13}$

There were no differences between the open and the laparoscopic approaches in the prevalence of postoperative complications. The percentage was approximately similar to other studies regarding recurrent hernias. ${ }^{10,15,16}$

The limitation of this study is the small number of subjects. With the greater number of primary hernioplasties performed with a mesh-based technique, collecting a large sample size for a recurrent hernia study is becoming increasingly difficult. The only possibility for evaluating recurrent hernia surgery is the multicenter trials. 


\section{Conclusion:}

Compared to open Lichtenstein hernioplasty, laparoscopic TEP approach for repair of recurrent inguinal hernia is technically feasible, safe and effective, with good clinical outcome. It is associated with longer operative time but reduced postoperative pain, analgesic requirement, and infection rate and earlier return to normal activities. The complication rate and recurrence rate were equal but patients were more satisfied.

\section{Reference:}

1- Legutko J, Pach R, Solecki R, Matyja A, Kulig J: The history of treatment of groin hernia. [Article in Polish] Folia Med Cracov 2008; 49(1-2): 57-74.

2- Lichtenstein IL, Shulman AG, Amid PK, Montllor MM: The tension-free hernioplasty. Am J Surg 1989; 157(2): 188-193.

3- Wara P, Bay-Nielsen M, Juul P, Bendix J, Kehlet $\mathrm{H}$ : Prospective nationwide analysis of laparoscopic versus Lichtenstein repair of inguinal hernia. Br J Surg 2005; 92(10): 1277-1281.

4- Liem MS, van der Graaf Y, Zwart RC, Geurts I, van Vroonhoven TJ: A randomized comparison of physical performance following laparoscopic and open inguinal hernia repair. The Coala Trial Group. $B r J$ Surg 1997; 84(1): 64-67.

5- Schiller A: Ergebnisse bei der Versorgung von Rezidivleistenhernien durch TEP. Dissertation Erlangen 2002.

6- Aeberhard P, Klaiber C, Meyenberg A, Osterwalder A, Tschudi J: Prospective audit of laparoscopic totally extraperitoneal inguinal hernia repair. A multicenter study of the Swiss Association for Laparoscopic and Thoracoscopic surgery. Surg Endosc 1999; 13(11): 1115-1120.

7- Chung RS, Rowland DY: Meta-analyses of randomized controlled trials of laparoscopic vs conventional inguinal hernia repairs. Surg Endosc 1999; 13(7): 689-694.

8- The Eu Hernia Trialist Collaboration: Laparoscopic compared with open methods of groin hernia repair: Systematic review of randomized controlled trials. Br J Surg 2000; 87(7): 860-867.

9- Heikkinen T, Bringman S, Ohtonen P, Kunelius P, Haukipuro K, Hulkko: A five-year outcome of laparo- scopic and
Lichtenstein hernioplasties. Surg Endosc 2004; 18: 518-522.

10- Kumar S, Nixon SJ, Macintyre IMC: Laparoscopic or Lichtenstein repair for recurrent inguinal hernia: One unit's experience. J R Coll Surg Edinb 1999; 44(5): 301-302.

11- Beets GL, Dirksen CD, Go PM, Geisler FE, Baeten CG, Kootstra G: Open or laparoscopic mesh repair for recurrent inguinal hernia? A randomized controlled trial? Surg Endosc 1999;13(4): 323-327.

12- Feliu X, Jaurrieta E, Viñas X, Macarulla E, Abad JM, Fernández-Sallent E: Recurrent inguinal hernia: A ten-year review. $J$ Laparoendosc Adv Surg Tech A 2004; 14(6): 362-367.

13- Richards SK, Vipond MN, Earnshaw JJ: Review of the management of recurrent inguinal hernia. Hernia 2004; 8(2): 144-148.

14- Barrat C, Surlin V, Bordea A, Champault G: Management of recurrent inguinal hernia: $A$ prospective study of 163 cases. Hernia 2003; 7(3): 125-129.

15- Eklund A, Rudberg C, Leijonmarck CE, Rasmussen I, Spangen L, Wickbom G, Wingren U, Montgomery A: Recurrent inguinal hernia. Randomized multicenter trial comparing laparoscopic and Lichtenstein repair. Surg Endosc 2007; 21(4): 634-640.

16- Dedemadi G, Sgourakis G, Karaliotas C, Christofides T, Kouraklis G, Karaliotas $\mathrm{C}$ : Comparison of laparoscopic and open tension-free repair of recurrent inguinal hernias: A prospective randomized study. Surg Endosc 2006; 20(7): 1099-1104 .

17- Scheuerlein H, Schiller A, Schneider C, Scheidbach H, Tamme C, Köckerling F: Totally extraperitoneal repair of recurrent inguinal hernia. Results from 179 consecutive patients. Surg Endosc 2003; 17(7): 1072-1076.

18- Tantia O, Jain M, Khanna S, Sen B: Laparoscopic repair of recurrent groin hernia: Results of a prospective study. Surg Endosc 2009; 23(4): 734-738.

19- SandbichlerP, DraxlH,Fuchs H,Furtschegger A, Egender G, Steiner E: Laparoscopic repair of recurrent inguinal hernias. Am J Surg 1996; 171(3): 366-368.

20- Huskisson EC: Measurement of pain. Lancet 1974; 2(7889): 1127-1131.

21- Www.asahq.org/.../ASA-Physical-StatusClassification-S ASA Physical Status Classification System.

22- Choi YY, Kim Z, Hur KY: The safety 
and effectiveness of laparoscopic total extraperitoneal (tep) repair for recurrent inguinal hernia after open hernioplasty. $J$ Laparoendosc Adv Surg Tech A 2010; 20(6): 537-539.

23- Lau H: Endoscopic totally extraperitoneal unguinal hernioplasty for recurrence after open repair. ANZ J Surg 2004; 74(10): 877-880.

24- Postlethwait RW: Recurrent inguinal hernia. Ann Surg 1985; 202(6): 777-779.

25- Weinstein M, Roberts M: Recurrent inguinal hernia. Follow-up study of 100 postoperative patients. Am J Surg 1975; 129(5): 564-569.

26- Aufenacker TJ, de Lange DH, Burg MD, Kuiken BW, Hensen EF, Schoots IG, Gouma DJ, Simons MP: Hernia surgery changes in the Amsterdam region, 1994-2001: Decrease in operations for recurrent hernia. Hernia 2005; 9(1): 46-50.

27- Bisgaard T, Bay-Nielsen M, Christensen IJ, Kehlet H: Risk of recurrence 5 years or more after primary Lichenstein mesh and sutured inguinal hernia repair. Br J Surg 2007; 94 (8): 1038-1040.

28- Scheuerlein H, Schiller A, Schneider C, Scheidbach H, Tamme C, Köckerling F:
Totally extraperitoneal repair of recurrent inguinal hernia: Results from 179 consecutive patients. Surg Endosc 2003; 17(7): 1072-1076.

29- Lau H: Endoscopic totally extraperitoneal unguinal hernioplasty for recurrence after open repair. ANZ J Surg 2004; 74(10): 877-880.

30- Garg P, Menon GR, Rajagopal M, Ismail M: Laparoscopic total extraperitoneal repair of recurrent inguinal hernias. Surg Endosc 2010; 24(2): 450-454.

31- Lowham AS, Filipi CJ, Fitzgibbons RJ Jr, Stoppa R, Wantz GE, Felix EL, Crafton WB: Mechanisms of hernia recurrence after preperitoneal mesh repair. Traditional and laparoscopic. Ann Surg 1997; 225(4): 422-431.

32- Schumpelick V, Kupczyk-Joeris D, Töns C, Pfingsten FP: Repair of recurrent inguinal hernia. Tactics, technic and results. Chirurg 1990; 61(7): 526-529.

33- Amid PK, Shulman AG, Lichtenstein IL: An analytic comparison of laparoscopic hernia repair with open "tension-free" hernioplasty. Int Surg 1995; 80(1): 9-17. 